\title{
The role of social media in primary care
}

\author{
Aneesa Abdul Rashid, Ahmed Kamarulzaman, Sakinah Sulong, Suhazeli Abdullah \\ Rashid AA, Kamarulzaman A, Sulong S, et al. The role of social media in primary care. Malays Fam Physician. 2021;16(2);14-18. \\ https://doi.org/10.51866/rv1048
}

\section{Keywords:}

Social media, doctors,

primary care, digital,

healthcare

\section{Authors:}

\author{
Aneesa Abdul Rashid \\ (Corresponding author) \\ MBBCh BAO (NUI), Dr FamMed \\ (UKM) \\ Deparment of Family Medicine, \\ Faculty of Medicine and Health \\ Sciences, Universiti Putra Malaysia \\ Selangor, Malaysia \\ Email: aneesa@upm.edu.my
}

Islamic Medical Association of

Malaysia (IMAM) Response and

Relief Team (IMARET)

Cheras, Wilayah Persekutuan

Kuala Lumpur, Malaysia

Malaysian Research Institute on

Ageing, Universiti Putra Malaysia

Serdang, Selangor, Malaysia

\section{Ahmed Kamarulzaman \\ MD (Volgograd) \\ Persatuan Pembanteras Mitos \\ Perubatan Malaysia (Medical \\ Mythbusters Malaysia) \\ Selangor, Malaysia}

Klinik Awfa, KotaSAS, B2 \& B4

Kuantan, Pahang Darul Makmur

Malaysia

\section{Sakinah Sulong}

Persatuan Pembanteras Mitos

Perubatan Malaysia (Medical

Mythbusters Malaysia)

Selangor, Malaysia

Klinik Kesihatan Masai,

Johor Bahru, Johor

Malaysia

\begin{abstract}
Online activities have become the norm. From searching for new information to conducting business meetings, social media's role in daily life continues to grow in prominence. It is estimated that the majority of the population uses social media, and users include doctors and other healthcare professionals. It is critical for primary care doctors to note how social media can substantially influence one's healthcare behaviour and decision making. Because primary care doctors are usually the first line of contact for patients, they are the most easily accessible and most instrumental in using social media to steer the public toward proper information on healthcare.
\end{abstract}

\section{Introduction}

It is estimated that there were nearly 4.4 billion internet users worldwide in 2019, a statistic reflective of roughly a $10 \%$ increase over that in 2018. Among internet users, 3.26 billion use social media (SM). ${ }^{1}$ In Malaysia, $87.4 \%$ of the population are internet users and the around $40 \%$ of users spend an estimated one to four hours online daily, which is a significant amount of time. It is reported that $85.6 \%$ of users spend their time online for networking, and the most popular sites include Facebook, Instagram and YouTube. ${ }^{2}$ These simple data alone illustrate the incontrovertible significance of SM in daily life.

\section{Roles and Benefits of SM}

In the United States, it has been reported that up to $80 \%$ of internet users have searched online for health information, which may influence their medical decision making and health-related behaviors. ${ }^{3}$ A study conducted on an online support group for patients with prostate cancer found that almost onethird (29\%) revised their initial treatment decisions after joining the support group. The researchers also learned that these patients demanded a more active role in the patientdoctor relationship and they also had more participation in conventional support groups. The above is an example that demonstrates the significance of online health communications with patients' decision making. ${ }^{4}$

There are many ways that doctors use SM and that transcend the professional-recreational bridge. Recreational use of SM involves interaction with individuals and elements outside of professional contexts, such as communication with relatives and friends, consumption entertainment-related content or participation in online pastimes. The use of SM is crucial in this era of digital living, but may engender negative consequences; several factors require consideration during SM use, such as potential disrespect for confidentiality, the possibility of misuse of SM platforms by patients and the risk of uploading unprofessional content. ${ }^{5}$ Specifically for healthcare researchers and clinicians, use of SM is predominantly for both recreational and professional purposes. In a study that investigated this matter, more than one-quarter of the participants, who included healthcare practitioners and clinicians, used SM to search for research evidence, but only $15 \%$ of the participants disseminated their research findings via SM. Among the challenges faced was lack of training in SM use for professionals and concerns regarding the trustworthiness of information obtained via SM. ${ }^{6}$ However, the younger generation appears more comfortable with the use of SM, which remains a popular mainstay among medical students and medical trainees, ${ }^{7}$ more than $90 \%$ of whom use SM. ${ }^{8}$

\section{Challenges of SM}

A major concern about SM use is the dissemination of incorrect health information. There are many instances in which non-health professionals who are nevertheless influential to the public relay false information. This is a worrying trend that sometimes causes detrimental consequences on a grand scale. For example, one seller may claim that the miracle pill it offers can cure numerous illnesses, only for consumption of the pull to result in end-stage renal failure and Cushing's 
Suhazeli Abdullah

MD(USM, MMed (FamMed)(UKM)

Persatuan Pembanteras Mitos

Perubatan Malaysia (Medical

Mythbusters Malaysia)

Selangor, Malaysia

Klinik Kesihatan Tengkawang

Kuala Berang, Terengganu, Malaysia
Disease among customers. A recent paper published on analysis of popular Englishlanguage videos about COVID-19 on YouTube reported that over one-quarter of the videos were non-factual and contained misleading information about the disease itself as well as conspiracy theories. These videos nonetheless garnered over 62 million views collectively. Meanwhile, in Malaysia, SM has been reported to be a source of support and encouragement for dangerous health beliefs such as unassisted home birth and refusal of routine vaccination for children. ${ }^{10,11}$

The danger of false information via SM stems from SM platforms' ability to disseminate information within a small amount of time but within a large radius. The impact may be limited to small numbers of contacts within a family or a social circle, or the information may circulate widely during critical situations such as natural disasters and political unrest. Currently, it is still controversial whether this type of information brings more benefit than harm. Rumours triggered via SM may cause catastrophic results; ${ }^{12}$ during the COVID-19 pandemic, a study in Iraq demonstrated a significant positive correlation between information shared via SM and public panic. The researchers reported that the 18-35-year age group was most affected psychologically. ${ }^{13}$ However, the influence of SM on manmade and natural disasters varies significantly. In response to the former, SM functions as a fount of emotional communication that relies heavily on opinionated pundits prone to the generation of rumours. In contrast, in the build-up to and aftermath of natural disasters, SM works as a means of information dissemination for risk communication. ${ }^{14}$

SM circles most often involve close family members, friends and acquaintances with common interests. Studies have shown family dynamics tend to have an impact on the health of a patient, ${ }^{15}$ and similarly, SM significantly influences psychological wellbeing. ${ }^{16}$ These are important elements likely to affect the management of patients.

\section{Suggestions to Overcome the Challenges}

The role of primary care doctors is essential in today's age of the digital era because of their status as the first line of contact for patients, and they must communicate proper and verified health information, knowledge and support to patients. This responsibility does not come without its challenges; the rapid spread of information makes it difficult for doctors to remain informed about newer verified information, and as a result, they may not be as influential in patients' lives as they should be.

With these factors in mind, here are four components in what primary care doctors can do to be involved with social media particularly in the digital era (see Table 1 for summary):

Table 1: Using SM in Primary Care

\begin{tabular}{llll}
\hline No & Suggestions & Comments \\
\hline 1 & Right Mindset & - & Acknowledge the importance of SM \\
& & - & Stay updated on current trends in health topics \\
\hline 2 & Right Planning & - & Actively discuss current trends with other healthcare professionals \\
\hline 3 & Right Support & - & Maintain an online presence and support colleagues \\
& & - & Conduct further research \\
\hline 4 & Right Model & - & Maintain professionalism, even online \\
& & - & Refrain from sharing patient information and stay general \\
& & - & Avoid private consultations \\
\hline
\end{tabular}

\section{Right Mindset}

\section{Acknowledge the importance of SM}

Healthcare professionals may feel that the use of SM should be restricted to recreational or social purposes only and outside of working hours, or they may exhibit diffidence about or ignorance of SM use; ${ }^{6,17}$ with this mindset, many may fail to acknowledge the importance of $\mathrm{SM}$ in the management of patients. In a nationwide study in Australia, primary care doctors were reported to use SM more than hospital-based specialists did, thereby highlighting the potential of these platforms' use. ${ }^{17}$ It is essential that primary care doctors be aware of this matter because disregarding SM and its content as of little importance may cause resentment among patients and later prompt them to find inaccurate information elsewhere, such as on 'alternative' treatments with little or no 
scientific evidence. ${ }^{10,11}$ As gatekeepers, it is essential for healthcare professionals to acknowledge the ideas, concerns and expectations of their patients, even if SM has influenced all three. For doctors without a SM presence, acknowledgment of an issue is an essential primary step, with subsequent advising of the patient as needed. Often, patients may echo the queries of their family members or peers, who may influence one's health decisions, ${ }^{15}$ which underscores the necessity for doctors to attend to queries on health-related issues on SM.

\section{Stay updated on current trends in health topics}

For those with a SM presence, keeping abreast of the latest health-related issues is paramount and will help primary care doctors to answer queries that they may field during consultation. For example, researchers have looked into Malaysian parents' opposition to childhood vaccination and suggested that online influence may be one of the key contributing factors to this negative behavior. ${ }^{11}$ The researchers also suggested that understanding the factors behind this influence can enhance the communication between the doctor and patient. ${ }^{11}$ However, alternatively, if doctors do not have SM accounts, engaging in discussions via WhatsApp group can suffice as an alternative. Doctors who remain updated and maintain an active SM presence must be conscious that some colleagues may not have SM accounts.

\section{Right Planning}

Actively discuss current trends with other healthcare professionals

Cooperation in active correspondence about SM health-related issues is also significant, ${ }^{11}$ and several nongovernmental organizations (NGOs) discuss these matters on a regular basis. NGOs, particularly healthcare NGOs, serve as common platforms for dissemination of up-to-date information to the public via various platforms. ${ }^{5}$ Discussions among different bodies consisting of both governmental organizations and $\mathrm{NGOs}$ that are usually held to discuss current issues and subsequently relay important information to the public by different mediums are mostly conducted through SM. For example, the Malaysian Ministry of Health has an official website to relay information to the public to avoid confusion and is regarded as a strong source of validated information.18 This collection of endeavours helps to disseminate proper information and sends a strong, professional, united message to the masses.

\section{Right Support}

Maintain an online presence and support colleagues

An SM 'influencer' is an individual with a large following on SM and/or who is influential on one or multiple platforms. ${ }^{19}$ The online community (collectively, 'netizens') take what influencers say rather seriously, sometimes to the degree of prompting immediate action; for example, an influencer may rapidly increase awareness on an issue and raise funds via crowdfunding. ${ }^{20}$ Being a SM influencer or having an influential SM account may not be suitable for every primary care doctor, but supporting colleagues in their plight to educate the public will send a strong message on the importance of a certain issue and will help in halting the spread of false information. Even sharing and liking posts on SM can generate a positive effect. One reason why medical myths and pseudoscience remain popular among netizens is because of the strong and effective online presence of influencers, who are interactive with their audience and find unique, engaging ways to communicate. Even if a doctor does not have a great number of followers on their SM pages, making a statement on health-related issues will help their close friends and family understand the matter better. Doctors who may not be influencers still have the capacity to influence others, albeit at a smaller level; advocate proper health-related information; and become valuable assets to their communities. ${ }^{21}$

\section{Conduct further research}

More research into this matter is required because how SM affects patients, particularly in primary care settings, is of utmost importance. Effective online communication by way of storytelling in real-life scenarios is one means by 
which people or organizations use SM to influence netizens, but future studies should investigate how SM affects health beliefs to promote good health behaviour. Without further analysis, the consequences may be detrimental, thereby complementing current ubiquitous problems such as unnecessary panic and ingestion of harmful substances thought to be preventative. ${ }^{13,22}$

\section{Right Model}

Maintain professionalism, even online $e^{23}$ Doctors should practice the code of professional conduct both in person and online, especially if patients are able to access their doctors' SM accounts. Offensive language and prejudiced words easily backfire in online platforms, and the effects may reverberate offline. Even online, there are rules that all healthcare professionals with SM accounts should follow to garner respect from colleagues and patients alike.

\section{Refrain from sharing patient information and stay general}

Sometimes, doctors share information on SM in an effort to educate patients or share their experiences without realizing that they have breached confidentiality. Patients' pictures (including documents such as X-rays) should only be uploaded with consent, ${ }^{21}$ especially written consent. If a posted photograph features a patient, the eyes should be covered to protect the patient's privacy. Doctors should be wary of exposing any form of patient identification, such as a patient's location, name or identity number, and instead, they should use general language and either keep their patients anonymous or employ pseudonyms.

\section{Avoid private consultations}

It is common for doctors to field personal and private questions on health on their SM platforms. Because of the limitations of SM and its informal nature, proper consultation in clinical settings is safer for diagnosis and management of patients' conditions. Formal online consultations should be via recognized mediums with strict standards of procedures. ${ }^{21}$

\section{Conclusion}

SM plays an important role in disseminating information to the general public. Primary care doctors may be among the first healthcare contacts to validate or invalidate the healthcare information that they obtain. The main goal of doctors in primary care is to use SM to address health concerns, particularly about information that patients retrieve from SM; establish better communication; and improve health education. There are numerous challenges that primary care doctors face when using SM, but they may overcome the most salient challenges by implementing the optimal mindset, planning, support and model, as described above.

\section{Acknowledgements}

None.

\section{Conflicts of Interest}

None.

\section{Funds}

None.

\section{References}

1. We Are Social Inc. Digital 2019: Global Internet Use Accelerates [Internet]. We Are Social. 2019 [cited 2020 Jun 12]. Available from: https://wearesocial.com/blog/2019/01/ digital-2019-global-internet-use-accelerates

2. Internet Users Survey $\mid$ Malaysian Communications and Multimedia Commission (MCMC) [Internet]. Malaysian Communications and Multimedia Commission (MCMC) | Suruhanjaya Komunikasi dan Multimedia Malaysia (SKMM). 2018 [cited 2020 Jan 18]. Available from: https://www.mcmc.gov.my/en/ resources/statistics/internet-users-survey
3. Fox S. The Social Life of Health Information, 2011 [Internet]. Pew Research centre: Internet \& Technology. 2011 [cited 2020 Jun 16]. Available from: https:/www.pewresearch.org/ internet/2011/05/12/the-social-life-of-healthinformation-2011/

4. Huber J, Maatz P, Muck T, Keck B, Friederich H-C, Herzog W, et al. The effect of an online support group on patients' treatment decisions for localized prostate cancer: An online survey. Urol Oncol Semin Orig Investig. 2017 Feb;35(2):37.e19-37.e28.
5. Rashid AA, Devaraj NK. Doctors and Social Media - Good, Bad or Both? A Malaysian Perspective. Int J Hum Health Sci IJHHS. 2020 Feb 19;4(3):174.

6. Tunnecliff J, Ilic D, Morgan P, Keating J, Gaida JE, Clearihan L, et al. The Acceptability Among Health Researchers and Clinicians of Social Media to Translate Research Evidence to Clinical Practice: Mixed-Methods Survey and Interview Study. J Med Internet Res. 2015 May 20;17(5):e119. 
7. George DR, Green MJ. Beyond Good and Evil: Exploring Medical Trainee Use of Social Media. Teach Learn Med. 2012 Apr;24(2):155-7.

8. Bosslet GT, Torke AM, Hickman SE, Terry CL, Helft PR. The Patient-Doctor Relationship and Online Social Networks: Results of a National Survey. J Gen Intern Med. 2011 Oct;26(10):1168-74.

9. Li HO-Y, Bailey A, Huynh D, Chan J. YouTube as a source of information on COVID-19: a pandemic of misinformation? BMJ Glob Health. 2020 May;5(5):e002604.

10. Ahmad Tajuddin NAN, Suhaimi J, Ramdzan SN, Malek KA, Ismail IA, Shamsuddin NH, et al. Why women chose unassisted home birth in Malaysia: a qualitative study. BMC Pregnancy Childbirth. 2020 Dec;20(1):309.

11. Rumetta J, Abdul-Hadi H, Lee Y-K. A qualitative study on parents' reasons and recommendations for childhood vaccination refusal in Malaysia. J Infect Public Health. 2020 Feb;13(2):199-203.

12. Pee LG. Trust of Information on Social Media: An Elaboration Likelihood Model. In: CONFIRM 2012 Proceedings [Internet]. 2012. p. 9. Available from: http://aisel.aisnet.org/ confirm2012/29
13. Ahmad AR, Murad HR. The Impact of Social Media on Panic During the COVID-19

Pandemic in Iraqi Kurdistan: Online Questionnaire Study. J Med Internet Res. 2020;22(5):e19556.

14. Liu T, Zhang H, Zhang H. The Impact of Social Media on Risk Communication of Disasters-A Comparative Study Based on Sina Weibo Blogs Related to Tianjin Explosion and Typhoon Pigeon. Int J Environ Res Public Health. 2020 Jan 31;17(3):883.

15. Wickrama K a. S, Lorenz FO, Wallace LE, Peiris L, Conger RD, Elder GH. Family Influence on Physical Health During the Middle Years: The Case of Onset of Hypertension. J Marriage Fam. 2001;63(2):527-39.

16. Abi-Jaoude E, Naylor KT, Pignatiello A. Smartphones, social media use and youth mental health. CMAJ. $2020 \mathrm{Feb}$ 10;192(6):E136-41.

17. Brown J, Ryan C, Harris A. How Doctors View and Use Social Media: A National Survey. J Med Internet Res. 2014;16(12):e267.

18. Liew SM, Khoo EM, Cheah WK, Peariasamy K, Ibrahim HM. We have to write and share valid and reliable information on COVID-19. Malays Fam Physician. 2020;15(1):1.
19. Frenberg K, Graham K, McGaughey K, Frenberg LA. Who are the social media influencers? A study of public perceptions of personality. Public Relat Rev. 2011 Mar 1;37(1):90-2.

20. Amirul Ihsan SL. Vivy Yusof and Fadza Anuar start fund for Covid-19 front liners. New Strait Times [Internet]. 2020 Mar 18 [cited 2020 Jun 9]; Available from: https://www.nst.com.my/ lifestyle/flair/2020/03/575658/vivy-yusof-andfadza-anuar-start-fund-covid-19-front-liners

21. Chretien Katherine C., Kind Terry. Social Media and Clinical Care. Circulation. 2013 Apr 2;127(13):1413-21.

22. Santos G, Gasca J, Parana R, Nunes V, Schinnoni M, Medina-Caliz I, et al. Profile of herbal and dietary supplements induced liver injury in Latin America: A systematic review of published reports. Phytother Res [Internet]. [cited 2020 Oct 7];n/a(n/a). Available from: https://onlinelibrary.wiley.com/doi/ abs/10.1002/ptr.6746

23. Kementerian Kesihatan Malaysia. Tata Etika Pengunaan Media Sosial Oleh Warga KKM. KKM, Putrajaya; 2016. 